Minoru Takashima • Kinya Ishikawa • Utako Nagaoka

Shin'ichi Shoji • Hidehiro Mizusawa

\title{
A linkage disequilibrium at the candidate gene locus for $16 q$-linked autosomal dominant cerebellar ataxia type III in Japan
}

Received: October 25, 2000 / Accepted: January 5, 2001

\begin{abstract}
We previously mapped the gene responsible for autosomal dominant cerebellar ataxia (ADCA) type III to a 10.9-cM interval between D16S3089 and D16S515 on chromosome 16q. This region, however, was identical to the candidate locus of spinocerebellar ataxia type 4 (SCA4). In this study, we extended our research to refine the gene locus of the disease by applying linkage disequilibrium with 20 microsatellite DNA markers. With 9 markers flanked by D16S3031 and D16S3107, we found that the affected individuals in six families had a common haplotype on their disease chromosomes. Furthermore, linkage disequilibrium was demonstrated with 5 informative markers: D16S3019 $(P=0.013), \mathrm{D} 16 \mathrm{~S} 3067(P=0.008), \mathrm{D} 16 \mathrm{~S} 3141(P=0.011)$, D16S496 $(P=0.032)$, and D16S3107 $(P=0.000)$. These results indicate that the disease could have originated from a common ancestor harboring a mutation within a less than 3-cM region between D16S3043 and D16S3095. The founder alleles were also observed in other patients with ADCA type III unrelated to the six families.
\end{abstract}

Key words Autosomal dominant cerebellar ataxia type III (ADCA type III) - Pure cerebellar ataxia - Spinocerebellar ataxia type 4 (SCA4) · Linkage disequilibrium · Founder effect $\cdot 16 q$-linked ADCA type III

\section{Introduction}

Autosomal dominant cerebellar ataxia (ADCA) is a clinically, pathologically, and genetically heterogeneous group of neurodegenerative disorders (Harding 1982). It is clini-

M. Takashima $\cdot$ K. Ishikawa $\cdot$ U. Nagaoka $\cdot$ H. Mizusawa $(\bowtie)$ Department of Neurology and Neurological Science, Tokyo Medical and Dental University, Graduate School of Medical and Dental Sciences, 1-5-45 Yushima, Bunkyo-ku, Tokyo 113-8519, Japan

Tel. +81-3-5803-5233; Fax +81-3-5803-0134

e-mail: h-mizusawa.nuro@tmd.ac.jp

S. Shoji

Department of Neurology, Institute of Clinical Medicine, University of Tsukuba, Tsukuba, Japan cally characterized by progressive ataxia of limbs and trunk, and dysarthria. It has been classified into three types by its clinical features (Harding 1982), with ADCA type III being clinically characterized by pure cerebellar ataxia throughout different generations (Harding 1982; Ishikawa et al. 1996). Recent developments in molecular genetics have elucidated 13 genetic mutations or gene loci of ADCAs. In relation to the clinical and pathological features of these ADCAs, SCA5 (Ranum et al. 1994), SCA6 (Zhuchenko et al. 1997), SCA10 (Matsuura et al. 1999; Zu et al. 1999), and SCA11 (Worth et al. 1999) are compatible with ADCA type III. SCA5 is linked to chromosome 11 (Ranum et al. 1994). The mutation causing SCA6 is the mildly expanded trinucleotide repeat in the $\alpha 1 \mathrm{~A}$-voltage-dependent calcium channel gene (CACNA1A) (Zhuchenko et al. 1997). The disease-causing mutation in SCA10 was revealed to be an intronic ATTCT pentanucleotide repeat (Matsuura et al. 2000). In one family, SCA11 was reported to be linked to chromosome 15q14-21.3 (Worth et al. 1999). A locus for one Japanese family with cerebellar ataxia and intermittent myoclonus was mapped to an interval on chromosome 19q13.4-qter (SCA14) (Yamashita et al. 2000). Although further studies of more cases should be done, SCA14 could be classified as ADCA type III.

We previously mapped the gene of another ADCA type III to chromosome $16 \mathrm{q}$ by linkage analysis (Nagaoka et al. 2000). By haplotype analysis, we found obligate recombinations with the centromeric marker D16S3089 and the telomeric marker D16S515. Together with the result of multipoint analysis, we assigned the gene locus to a 10.9-cM interval between D16S3089 and D16S515. This region was identical to the candidate locus of SCA4 (Flanigan et al. 1996), indicating that SCA4 and this 16q-linked ADCA type III could be allelic disorders. However, we noted significant differences in their clinical features. SCA4 is characterized by cerebellar ataxia with sensory axonal neuropathy (Flanigan et al. 1996), whereas none of our patients with ADCA type III showed obvious sensory disturbance (Nagaoka et al. 2000).

Toward identification of the gene mutation in the 16qlinked ADCA type III, we typed 15 microsatellite DNA 
markers between D16S3089 and D16S515, and searched for the presence of the haplotype commonly seen in six families with the 16q-linked. ADCA type III that we examined previously (Ishikawa et al. 1997). Analyzing allele frequencies in a normal Japanese population sample also allowed us to examine linkage disequilibrium. Here, we show that we were able to narrow the candidate gene locus to a less than $3-\mathrm{cM}$ region on chromosome $16 \mathrm{q}$.

\section{Subjects and methods}

The 16q-linked ADCA type III pedigrees in this study

Six Japanese families (P2, P4, P6, P12, P14, and P15) were investigated. They were the subjects of our previous study (Ishikawa et al. 1997). The cardinal clinical manifestation of the 28 affected individuals was pure cerebellar ataxia. Extracerebellar signs and symptoms were not observed (Nagaoka et al. 2000). Their precise clinical characteristics have been described previously (Ishikawa et al. 1997; Nagaoka et al. 2000).

\section{Normal controls}

Thirty-four Japanese people without any neurodegenerative diseases themselves, or in their pedigrees, were examined. Their average age at examination was $58.4 \pm 12.7$ years.

Markers, genotyping, and linkage disequilibrium

We (Nagaoka et al. 2000) had previously examined 5 markers in the region between D16S3089 and D16S515 (D16S3089, D16S3050, D16S3043, D16S3107, and D16S515). In this study, we examined all 15 remaining microsatellite linkage markers (Genethon, Evry, France) in the region between D16S3089 and D16S515 (Dib et al. 1996), suggesting that all 20 markers within the 10.9-cM region have been examined. The relative distances of the 20 markers were: 16 centromere (cen)-D16S3089-5.0-cMD16S3050-0.0-cM-D16S3043-0.6-cM-D16S3031-0.6-cMD16S3019-0.0-cM-D16S3067-0.1-cM-D16S3141-0.0cM-D16S496-0.0-cM-D16S3086-0.0-cM-D16S421-0.0-cMD16S3085-0.0-cM-D16S3107-1.1-cM-D16S3095-1.1-cMD16S3059-0.0-cM-D16S3106-0.0-cM-D16S3025-0.0cM-D16S3139-1.4-cM-D16S3066-0.1-cM-D16S512-2.1-cMD16S515-16q telomere (ter).

Genomic DNA was amplified by polymerase chain reaction (PCR), and genotypes were determined with an automated DNA sequencer (Pharmacia Biotech, Sweden), as previously described (Ishikawa et al. 1996; Ishikawa et al. 1997). Haplo-types were constructed with the 20 markers by visual inspection. Linkage disequilibrium was statistically analyzed by Fisher's exact probability test.
Other individuals affected with ADCA type III

To see whether the haplotype commonly seen in the six families linked to chromosome $16 \mathrm{q}$ was also present in other patients with hereditary ataxia, we analyzed nine patients with an autosomal dominant mode of inheritance who were unrelated to the six families. They were excluded for known mutations of other SCAs (SCA1, SCA2, MJD/SCA3, SCA6, SCA7, SCA8, and SCA12).

The clinical features of these nine patients were pure cerebellar ataxia and could be classified as ADCA type III. Cases 3 and 4 were siblings. Genotypes were determined for nine markers, D16S3031, D16S3019, D16S3067, D16S3141, D16S496, D16S3086, D16S421, D16S3085, and D16S3107. We arbitrarily deduced haplotypes from their genotypes.

\section{Results}

Haplotype analysis in the six 16q-linked ADCA type III families

In this study, we detected no recombination events with 15 new markers spaced between D16S3089 and D16S515. When haplotypes were constructed, we found that the affected individuals and carriers in all six families had a common haplotype for the nine markers, D16S3031, D16S3019, D16S3067, D16S3141, D16S496, D16S3086, D16S421, D16S3085, and D16S3107. That is, 9(276-bp)-4(248-bp)5(147-bp)-3(244-bp)-5(222-bp)-2(187-bp)-3(218-bp)-2(202bp)-7(302-bp). However, haplotypes with the other 11 of the total of 20 markers examined, except for the two markers D16S3025 and D16S3139, were not shared (Table 1). These two markers, D16S3025 and D16S3139, were considered to be not informative, because we found high allele frequencies for the two markers in the general population, of $75.0 \%$ and $81.6 \%$, respectively (Table 1). These results may indicate that the haplotype 9-4-5-3-5-2-32-7 could have originated from a common founder and that the responsible gene could exist in the less than 3-cM region between D16S3043 and D16S3095.

Linkage disequilibrium with five of the nine markers in the region was significant: D16S3019 $(P=0.013), \mathrm{D} 16 \mathrm{~S} 3067$ $(P=0.008), \mathrm{D} 16 \mathrm{~S} 3141(P=0.011), \mathrm{D} 16 \mathrm{~S} 496(P=0.032)$, and D16S3107 $(P=0.000)$ (Table 1). On the other hand, it was not significant with the other four markers, D16S3031, D16S3086, D16S421, and D16S3085, in which the allele frequencies in the general population were high (Table 1).

Deduced haplotype with the other ADCA type III patients

The genotypes of the nine other ADCA type III patients are shown in Table 2. When the haplotypes were deduced from their genotypes to match the haplotype 9-4-5-3-5-2-32-7 as much as possible, we found that cases $1-3$ and 6 could share this haplotype (Table 2). Therefore four of the nine 
Table 1. Linkage disequilibrium for 20 markers on the candidate region on chromosome $16 \mathrm{q}$

\begin{tabular}{|c|c|c|c|c|c|c|c|c|c|}
\hline \multirow[b]{2}{*}{ DNA marker } & \multirow[b]{2}{*}{ Locus } & \multicolumn{6}{|c|}{$\begin{array}{l}\text { Haplotype of disease choromosome for } 16 q \text {-linked ADCA } \\
\text { type III pedigrees }\end{array}$} & \multirow{2}{*}{$\begin{array}{l}\text { Allele } \\
\text { frequency in } \\
\text { general } \\
\text { population } \\
(\%)\end{array}$} & \multirow{2}{*}{$\begin{array}{l}\text { Linkage } \\
\text { disequilibrium } \\
(P \text { value })\end{array}$} \\
\hline & & $\mathrm{P} 2$ & P4 & P6 & P12 & P14 & P15 & & \\
\hline D16S3089 & & 7 & 2 & 9 & 10 & 1 & 9 & - & - \\
\hline D16S3050 & & 2 & 5 & 4 & 2 & 8 & 4 & - & - \\
\hline D16S3043 & & 2. & 2. & 3. & 4 & 6 & 3 & - & - \\
\hline D16S3031 & & 9 & 9 & $\dot{9}$ & $\dot{9}$ & $\dot{9}$ & 9 & 68.1 & 0.113 \\
\hline D16S3019 & & 4 & 4 & 4 & 4 & 4 & 4 & 45.8 & $0.013 *$ \\
\hline D16S3067 & & 5 & 5 & 5 & 5 & 5 & 5 & 41.9 & $0.008 *$ \\
\hline D16S3141 & $16 q 13$ & 3 & 3 & 3 & 3 & 3 & 3 & 44.4 & $0.011 *$ \\
\hline D16S496 & & 5 & 5 & 5 & 5 & 5 & 5 & 54.2 & $0.032 *$ \\
\hline D16S3086 & & 2 & 2 & 2 & 2 & 2 & 2 & 65.7 & 0.093 \\
\hline D16S421 & & 3 & 3 & 3 & 3 & 3 & 3 & 75.7 & 0.205 \\
\hline D16S3085 & & 2 & 2 & 2 & 2 & 2 & 2 & 81.8 & 0.320 \\
\hline D16S3107 & & 7. & 7. & 7. & 7 & 7 & 7. & 13.9 & $0.000 *$ \\
\hline D16S3095 & & 2 & 3 & 1 & 1 & 1 & 1 & - & - \\
\hline D16S3059 & & 5 & 3 & 7 & 7 & 7 & 7 & - & - \\
\hline D16S3106 & & 2 & 3 & 2 & 2 & 2 & 2 & - & - \\
\hline D16S3025 & & 4 & 4 & 4 & 4 & 4 & 4 & 75.0 & 0.215 \\
\hline D16S3139 & $16 q 21$ & 2 & 2 & 2 & 2 & 2 & 2 & 81.6 & 0.329 \\
\hline D16S3066 & & 4 & 1 & 4 & 4 & 1 & 4 & - & - \\
\hline D16S512 & & 5 & 4 & 5 & 4 & 1 & 5 & - & - \\
\hline D16S515 & & 5 & 5 & 8 & 5 & 7 & 8 & - & - \\
\hline
\end{tabular}

* $P$ values show significant linkage disequilibrium by Fisher's exact probability test $(P<0.05)$

As shown by the horizontal bars in the P6 and P14 columns, we previously found two recombinations between the affected individuals in P6 and D16S3089 and between P14 and D16S515 (Nagaoka et al. 2000). Affected individuals and carriers in all six families have a common haplotype for the nine markers, D16S3031, D16S3019, D16S3067, D16S3141, D16S496, D16S3086, D16S421, D16S3085, and D16S3107. That is, 9-4-5-3-52-3-2-7 shown as boxed with dotted lines

ADCA, Autosomal dominant cerebellar ataxia

Table 2. Other ADCA type III patients and their genotypes for the nine markers, D16S3031, D16S3019, D16S3067, D16S3141, D16S496, D16S3086, D16S421, D16S3085, and D16S3107

Case no.

\begin{tabular}{|c|c|c|c|c|c|c|c|c|c|c|c|c|c|c|c|c|c|c|}
\hline \multirow{3}{*}{$\begin{array}{l}\begin{array}{l}\text { Clinical } \\
\text { diagnosis }\end{array} \\
\text { D16S3031 }\end{array}$} & \multicolumn{2}{|c|}{1} & \multicolumn{2}{|c|}{2} & \multicolumn{2}{|c|}{3} & \multicolumn{2}{|c|}{4} & \multicolumn{2}{|c|}{5} & \multicolumn{2}{|l|}{6} & \multicolumn{2}{|c|}{7} & \multicolumn{2}{|c|}{8} & \multicolumn{2}{|l|}{9} \\
\hline & \multicolumn{2}{|c|}{ ADCA III } & \multicolumn{2}{|c|}{ ADCA III } & \multicolumn{2}{|c|}{ ADCA III } & \multicolumn{2}{|c|}{$\begin{array}{l}\text { ADCA III } \\
\text { Case 3's brother }\end{array}$} & \multicolumn{2}{|c|}{ ADCA III } & \multicolumn{2}{|c|}{ ADCA III } & \multicolumn{2}{|c|}{ ADCA III } & \multicolumn{2}{|c|}{ ADCA III } & \multicolumn{2}{|c|}{ ADCA III } \\
\hline & 9 & 9 & 9 & 9 & 9 & 9 & 7 & 10 & 9 & 9 & 9 & 3 & 9 & 9 & 9 & 9 & 9 & 9 \\
\hline D16S3019* & 4 & 5 & 4 & 4 & 4 & 2 & 4 & $: 3$ & 1 & 3 & 4 & 4 & 3 & 3 & 4 & 4 & 4 & 5 \\
\hline D16S3067* & 5 & 3 & 5 & 5 & 5 & 5 & 5 & 5 & 5 & 8 & 5 & 5 & 5 & 7 & 5 & 8 & 4 & 7 \\
\hline D16S3141* & 3 & 9 & 3 & 3 & 3 & 3 & $: 3$ & $: 3$ & 3 & 6 & 3 & 4 & 3 & 3 & 5 & 5 & 3 & 6 \\
\hline D16S496* & 5 & 5 & 5 & 5 & 5 & 4 & $\therefore 5$ & 5 & 5 & 6 & 5 & 1 & 5 & 5 & 5 & 5 & 4 & 4 \\
\hline D16S3086 & 2 & 2 & 2 & 2 & 2 & 3 & $: 2$ & 3 & 2 & 3 & 2 & 2 & 2 & 3 & 3 & 3 & 2 & 2 \\
\hline D16S421 & 3 & 4 & 3 & 3 & 3 & 3 & 3 & 7 & 3 & 5 & 3 & 5 & 3 & 3 & 3 & 4 & 3 & 5 \\
\hline D16S3085 & 2 & 2 & 2 & 2 & 2 & 4 & $: 2$ & $: 2$ & 2 & 4 & 2 & 2 & 2 & 2 & 2 & 2 & 2 & 3 \\
\hline D16S3107* & 7 & 7 & 7 & 4 & 7 & 8 & $\therefore 7$ & 3 & 7 . & 7 & 7 & 6 & 6 & 6 & 5 & 6 & 7 & 8 \\
\hline
\end{tabular}

Cases 1-3 and 6 could have the haplotype 9-4-5-3-5-2-3-2-7 (shown as boxed with solid lines). Cases 4 and 5 could also have some parts of the haploytpe (shown as boxed with dotted lines). However, we could not determine whether these genotypes were located on the same chromosome. We recognized significant linkage disequilibrium with five DNA markers (shown with asterisks; see Table 1) 
affected individuals (44.4\%) with ADCA type III may have the same mutation as that in the 16q-linked ADCA type III.

\section{Discussion}

We found a common haplotype, 9-4-5-3-5-2-3-2-7, for the affected individuals and carriers with nine markers flanked by D16S3031 and D16S3107, and significant linkage disequilibrium was demonstrated with five of the nine markers within the region. We then estimated the prevalence of the haplotype 9-4-5-3-5-2-3-2-7 from the genotypes of unaffected controls. When we arbitrarily constructed this particular haplotype for them, only 2 of 64 chromosomes $(3.13 \%)$ had this haplotype. These findings suggest that this haplotype is specific for the 16q-linked ADCA type III, and that the Japanese families with the disease could have a single founder. Also, other types of ADCAs, such as SCA2 (Hernandez et al. 1995), SCA6 (Dichgans et al. 1999), and SCA7 (Johansson et al. 1998), have been reported to have founder effects in particular populations. We here show convincing data that the causative gene of the 16q-linked ADCA type III appears to be located on the less than 3-cM interval between D16S3043 and D16S3095 on chromosome 16q13. This region is located exactly inside the 6-cM interval between D16S514 and D16S512, where the SCA4 gene was mapped (Flanigan et al. 1996). (Authors' note: Flanigan et al. described their candidate region between D16S514 and D16S512 as being on chromosome 16q22.1 (Flanigan et al. 1996). However, from recent electronic databases, D16S514 was located on the region flanked by D16S3089 and D16S3050 on chromosome 16q13. D16S512 lay on chromosome 16q21, as we show in Table 1. The newly assigned region between D16S3043 and D16S3095 was exactly included in the $S C A 4$ region). Moreover, the causative gene may be located in the immediate vicinity of D16S3107 with the highest probability of linkage disequilibrium.

Linkage disequilibrium can be a powerful method for the identification of a causative gene, especially in genetically isolated countries or areas such as Finland and Japan. The method has played important roles in the identification of mutated genes in other hereditary diseases, such as diastrophic dysplasia (DTD) in Finland (Hästbacka et al. 1994) and Fukuyama-type congenital muscular dystrophy (FCMD) in Japan (Toda et al. 1996). Accordingly, we employed this method in our study.

Only the haplotype 9-4-5-3-5-2-3-2-7 could be a clue to the diagnosis of this type of ADCA type III at present. We examined the genotypes of nine other patients with hereditary cerebellar ataxia and deduced their haplotypes. Four of the nine affected individuals with ADCA type III (cases 13 and 6) could have the haplotype. Because case 4 , a brother of case 3, could have the haplotype 4-5-3-5-2-3-2-7 for the eight telomeric markers, he could, possibly, have the causative gene within the telomeric region between D16S3031 and D16S3095. Moreover, case 5 could share part of the haplotype (Table 2). In these nine patients, we could not find any affected persons with cerebellar ataxia and sensory neuropathy, such as occurs in patients with SCA4.

There is a report of some sporadic cases of SCA6, the major type of ADCA type III (Futamura et al. 1998). Therefore, we examined three sporadic patients with cerebellar ataxia. We investigated the deduced haplotype of the nine markers by the same method as that described above. One of the three patients with cerebellar ataxia could share this haplotype (data not shown). This observation indicates that a certain population of sporadic patients with cerebellar ataxia could harbor the same mutation as that in the patients or carriers in the six families with the 16q-linked ADCA type III.

Pathologically, predominant loss of Purkinje cells was detected in SCA6 (Ishikawa et al. 1999), which is a typical type of ADCA type III. Consequently, the mutated gene in the 16q-linked ADCA type III, which mainly shows pure cerebellar ataxia, may also have a close relationship to Purkinje cell loss. Identification of the causative gene of the 16q-linked ADCA type III would pave the way toward elucidation of the pathogenesis of ADCAs.

Acknowledgments We would like to thank the patients and their families who participated in this study. This work was supported by grants from the Research Committee for Ataxic Disease (to H.M.), from Genome Science Research, the Ministry of Health and Welfare of Japan (to H.M.), from Scientific Research on Priority Areas (C) Advanced Brain Science Project - from the Ministry of Education, Science, and Culture of Japan (to K.I.), and from the Nagao Takeshi Research Foundation for Intractable Disease (to K.I.)

\section{References}

Dib C, Faure S, Fizames C, Samson D, Drouot N, Vignal A, Millasseau P, Marc S, Hazan J, Seboun E, Lathrop M, Gyapay G, Morissette J, Weissenbach J (1996) A comprehensive genetic map of the human genome based on 5264 microsatellites. Nature 380:152-154

Dichgans M, Schols L, Herzog J, Stevanin G, Weirich-Schwaiger H, Rouleau G, Burk K, Klockgether T, Zuhlke C, Laccone F, Riess O, Gasser T (1999) Spinocerebellar ataxia type 6: evidence for a strong founder effect among German families. Neurology 52:849-851

Flanigan K, Gardner K, Alderson K, Galster B, Otterud B, Leppert MF, Kaplan C, Ptacek LJ (1996) Autosomal dominant spinocerebellar ataxia with sensory axonal neuropathy (SCA4): clinical description and genetic localization to chromosome 16q22.1. Am J Hum Genet 59:392-399

Futamura N, Matsumura R, Fujimoto Y, Horikawa H, Suzumura A, Takayanagi T (1998) CAG repeat expansions in patients with sporadic cerebellar ataxia. Acta Neurol Scand 98:55-59

Harding AE (1982) The clinical features and classification of the late onset autosomal dominant cerebellar ataxias. A study of 11 families, including descendants of the "the Drew family of Walworth". Brain 105:1-28

Hästbacka J, de la Chapelle A, Mahtani MM, Clines G, Reeve-Daly MP, Daly M, Hamilton BA, Kusumi K, Trivedi B, Weaver A, Coloma A, Lovett M, Buckler A, Kaitila I, Lander ES (1994) The diastrophic dysplasia gene encodes a novel sulfate transporter: positional cloning by fine-structure linkage disequilibrium mapping. Cell 78:1073-1087

Hernandez A, Magarino C, Gispert S, Santos N, Lunkes A, Orozco G, Heredero L, Beckmann J, Auburger G (1995) Genetic mapping of the spinocerebellar ataxia 2 (SCA2) locus on chromosome 12q23q24.1. Genomics 25:433-435

Ishikawa K, Mizusawa H, Saito M, Tanaka H, Nakajima N, Kondo N, Kanazawa I, Shoji S, Tsuji S (1996) Autosomal dominant pure cer- 
ebellar ataxia. A clinical and genetic analysis of eight Japanese families. Brain 119:1173-1182

Ishikawa K, Tanaka H, Saito M, Ohkoshi N, Fujita T, Yoshizawa K, Ikeuchi T, Watanabe M, Hayashi A, Takiyama Y, Nishizawa M, Nakano I, Matsubayashi K, Miwa M, Shoji S, Kanazawa I, Tsuji S, Mizusawa H (1997) Japanese families with autosomal dominant pure cerebellar ataxia map to chromosome 19p13.1-p13.2 and are strongly associated with mild CAG expansions in the spinocerebellar ataxia type 6 gene in chromosome 19p13.1. Am J Hum Genet 61:336-346

Ishikawa K, Watanabe M, Yoshizawa K, Fujita T, Iwamoto H, Yoshizawa T, Harada K, Nakamagoe K, Komatsuzaki Y, Satoh A, Doi M, Ogata T, Kanazawa I, Shoji S, Mizusawa H (1999) Clinical, neuropathological, and molecular study in two families with spinocerebellar ataxia type 6 (SCA6). J Neurol Neurosurg Psychiatry 67:86-89

Johansson J, Forsgren L, Sandgren O, Brice A, Holmgren G, Holmberg M (1998) Expanded CAG repeats in Swedish spinocerebellar ataxia type 7 (SCA7) patients: effect of CAG repeat length on the clinical manifestation. Hum Mol Genet 7:171-176

Matsuura T, Achari M, Khajavi M, Bachinski LL, Zoghbi HY, Ashizawa T (1999) Mapping of the gene for a novel spinocerebellar ataxia with pure cerebellar signs and epilepsy. Ann Neurol 45:407411

Matsuura T, Yamagata T, Burgess DL, Rasmussen A, Grewal RP, Watase K, Khajavi M, McCall AE, Davis CF, Zu L, Achari M, Pulst SM, Alonso E, Noebels JL, Nelson DL, Zoghbi HY, Ashizawa T (2000) Large expansion of the ATTCT pentanucleotide repeat in spinocerebellar ataxia type 10. Nat Genet 26:191-194

Nagaoka U, Takashima M, Ishikawa K, Yoshizawa K, Yoshizawa T, Ishikawa M, Yamawaki T, Shoji S, Mizusawa H (2000) A gene on
SCA4 locus causes dominantly inherited pure cerebellar ataxia. Neurology 54:1971-1975

Ranum LP, Schut LJ, Lundgren JK, Orr HT, Livingston DM (1994) Spinocerebellar ataxia type 5 in a family descended from the grandparents of President Lincoln maps to chromosome 11. Nat Genet 8:280-284

Toda T, Miyake M, Kobayashi K, Mizuno K, Saito K, Osawa M, Nakamura Y, Kanazawa I, Nakagome Y, Tokunaga K, Nakahori Y (1996) Linkage-disequilibrium mapping narrows the Fukuyamatype congenital muscular dystrophy (FCMD) candidate region to $<100 \mathrm{~kb}$. Am J Hum Genet 59:1313-1320

Worth PF, Giunti P, Gardner-Thorpe C, Dixon PH, Davis MB, Wood NW (1999) Autosomal dominant cerebellar ataxia type III: linkage in a large British family to a 7.6-cM region on chromosome 15q1421.3. Am J Hum Genet 65:420-426

Yamashita I, Sasaki H, Yabe I, Fukuzawa T, Nogoshi S, Komeichi K, Takada A, Shiraishi K, Takiyama Y, Nishizawa M, Kaneko J, Tanaka H, Tsuji S, Tashiro K (2000) A novel locus for dominant cerebellar ataxia (SCA14) maps to a 10.2-cM interval flanked by D19S206 and D19S605 on chromosome 19q13.4-qter. Ann Neurol 48:156-163

Zhuchenko O, Bailey J, Bonnen P, Ashizawa T, Stockton DW, Amos C, Dobyns WB, Subramony SH, Zoghbi HY, Lee CC (1997) Autosomal dominant cerebellar ataxia (SCA6) associated with small polyglutamine expansions in the alpha 1A-voltage-dependent calcium channel. Nat Genet 15:62-69

Zu L, Figueroa KP, Grewal R, Pulst SM (1999) Mapping of a new autosomal dominant spinocerebellar ataxia to chromosome 22. Am J Hum Genet 64:594-599 